\title{
Kesetaraan Kuat Tekan Batu Bata (Press) Asal Bangsal Mojosari Kabupaten Mojokerto Terhadap Kuat Tekan Spesi Campuran Semen, Kapur, dan Pasir untuk Pasangan Bata
}

\author{
Sukobar, Kuntjoro, Kusumastuti, Sungkono \\ Program Studi Diploma Teknik Sipil FTSP ITS, Surabaya \\ Email: Kobarabiyi@gmail.com
}

\begin{abstract}
Brick masonry is a building material normally used as wall element in residential and high rise buildings. It consists of brick and cement paste, use either as an ordinary wall or load bearing wall element. Brick comes from various areas, and is made using different method of fabrication, different material and composition. Therefore, there is a possibility that the brick used is either stronger than cement paste or vice versa. In this research, 30 bricks of $19 \mathrm{~cm} \times 9.5 \mathrm{~cm} \times 4.5 \mathrm{~cm}$ from Bangsal Mojosari in Mojokerto District are compression tested to get its compressive strength and will be compared with the strength of cement paste, made from limestone, sand, and Portland Cement (PC) type I with composition of 5:15:1. The cement content is varied from 0.6 to 1.3 by volume. The results of this study indicates that the average compressive strength of the bricks is around $149.85 \mathrm{~kg} / \mathrm{cm}^{2}$. Using regression analysis, the proportion of cement paste is 5:15:16 to obtain the compressive strength equal to the strength of the brick.
\end{abstract}

Keywords: bricks, paste, and compressive strength.

\section{Abstrak}

Pasangan batu bata merupakan material bangunan yang selalu dipergunakan khususnya untuk dinding rumah tinggal maupun gedung bertingkat. Elemen pasangan batu bata terdiri dari batu bata dan perekat (spesi), yang dipakai sehari-hari dalam pelaksanaan baik sebagai dinding penyekat maupun pemikul beban. Batu bata yang dipakai berasal dari daerah yang berbedabeda, serta cara pembuatan dan spesi yang dipergunakan juga dari bahan dan komposisi campuran yang berbeda-beda. Sehingga dalam pasangan batu bata tersebut kemungkinan batu batanya lebih kuat dari spesinya atau sebaliknya spesinya lebih kuat dari pada batu batanya. Dalam penelitian ini dilakukan pengetesan kuat tekan 30 benda uji batu bata yang diambil secara random pada 6 lokasi pembuatan dari Bangsal Mojosari Kabupaten Mojokerto yang berukuran $19 \mathrm{~cm} \times 9,5 \mathrm{~cm} \times 4,5 \mathrm{~cm}$ dan akan disetarakan kuat tekanannya dengan spesi hasil penelitian terdahulu (Sukobar, 1995) campuran 5 bagian kapur : 15 bagian pasir dan 1 bagian semen (PC) tipe 1 yang kadar/bagian semennya diubah-ubah dari 0,6 bagian sampai dengan 1,3 bagian. Hasil penelitian ini menunjukkan bahwa kuat tekan rata-rata dari 30 benda uji batu bata Press dari Bangsal Mojosari Kabupaten Mojokerto adalah sebesar $149.85 \mathrm{~kg} / \mathrm{cm}^{2}$, dengan menggunakan persamaan regresi hasil penelitian terdahulu (Sukobar, 1995) maka kekuatan tekannya setara dengan spesi campuran 5 bagian kapur : 15 bagian pasir dan 8 bagian semen. Model regresi kuat tekan spesi terhadap kadar semen adalah $Y=2,66+9,07 X$, dimana $Y$ adalah nilai kuat tekan dan $X$ adalah nilai kadar semen. Kesimpulan dari penelitian ini bahwa apabila membuat pasangan batu bata menggunakan batu bata Press dari Mojosari, maka spesinya menggunakan campuran 5 bagian kapur : 15 bagian pasir : 16 bagian semen agar kekuatan tekannya setara atau kuat tekan rata-rata batu bata (Press) dari Bangsal Mojosari setara dengan spesi campuran 5 bagian kapur : 15 bagian pasir : 16 bagian semen (PC) tipe 1.

Kata kunci: batu bata, spesi, dan kuat tekan.

\section{Pendahuluan}

Bangunan sederhana khususnya rumah tinggal merupakan kebutuhan untuk hunian yang terus meningkat, sesuai dengan data Badan Pusat Statisktik
(BPS) saat ini, pertumbuhan Masyarakat Berpenghasilan Rendah (MBR) kian signifikan atau mencapai 60 juta orang pertahun (Erlangga Satria Agung, 2013). Kondisi perekonomian yang

Jurnal APLIKASI: Media Informasi \& Komunikasi Aplikasi Teknik Sipil Terkini Halaman 13 
kurang stabil akhir-akhir ini berdampak terhadap menurunnya daya beli masyarakat terhadap rumah sederhana, hal ini karena harga bahan-bahan bangunan khususnya pasir dan semen semakin melambung sehingga menyebabkan biaya pembuatan rumah sederhana semakin tinggi. Untuk mengurangi biaya tersebut dapat dilakukan dengan merekayasa elemen dinding tembok/pasangan bata sebagai pemikul beban yang terbuat/tersusun dari bahan batu bata dan spesi yang dibuat sedemikian rupa sehingga kuat tekan $(\sigma)$ batu bata setara dengan kuat tekan $(\sigma)$ spesi yang terbuat dari campuran semen, kapur, dan pasir. Dengan harapan dapat menghemat bahan perekat semen (Sukobar, 1995). Komponen spesi/mortar adalah sebagai berikut:

a). Kapur merupakan komponen bahan spesi/mortar yang diperoleh dari pembakaran batu kapur pada suhu tertentu kemudian dipadamkan dengan air. Kapur $\left(\mathrm{CaCo}_{3}\right)$ pada spesi/mortas berfungsi sebagai bahan pengikat yang berwarna putih.

b). Semen sebagai bahan pengikat yang digunakan adalah semen gresik Tipe 1, sement portland ada beberapa tipe adalah sebagai berikut:

- Tipe I (Ordinary Portland Cement) Yaitu sement portland untuk penggunaan umum yang tidak memerlukan persyaratan khusus, semen ini mengandung $5 \% \mathrm{MgO}$ dan 2,5$3 \% \mathrm{SO}_{3}$.

- Tipe II (Moderate Heat Portland Cement)

Yaitu sement portland yang dalam penggunaannya memerlukan keta- hanan terhadap sulfat dan panas hidrasi sedang, semen ini mengandung $20 \% \quad \mathrm{SiO}_{2}, \quad 6 \% \quad \mathrm{AL}_{2} \mathrm{O}_{3}$, $6 \% \mathrm{Fe}_{2} \mathrm{O}_{3}, 6 \% \mathrm{MgO}$, dan $8 \% \mathrm{C}_{3} \mathrm{~A}$.

- Tipe III (High Early Strenght Portland Cement)

Yaitu sement portland yang dalam penggunaannya memerlukan kekuatan tinggi pada fase permulaan setelah pengikatan terjadi, semen ini mengandung $3,5-4 \% \quad \mathrm{AL}_{2} \mathrm{O}_{3}, 6 \%$ $\mathrm{Fc}_{2} \mathrm{O}_{3}, 35 \% \mathrm{C}_{3} \mathrm{~S}, 6 \% \mathrm{MgO}, 40 \%$ $\mathrm{C}_{2} \mathrm{~S}$, dan $15 \% \mathrm{C}_{3} \mathrm{~A}$.

- Tipe IV (Low Heat Portland Cement)

Yaitu sement portland yang dalam penggunaannya memerlukan panas hidrasi rendah, semen ini mengandung $6,5 \% \mathrm{MgO}, 2,3 \% \mathrm{SO}_{3}$, dan $7 \%$ $\mathrm{C}_{3} \mathrm{~A}$.

- Tipe V (Super Sulphated Cement) Yaitu sement portland yang dalam penggunaannya memerlukan ketahanan tinggi terhadap sulfat, semen ini mengandung 5\% terak $\mathrm{Pc}, 6 \%$ $\mathrm{MgO}, 2,3 \% \mathrm{SO}_{3}$, dan $5 \% \mathrm{C}_{3} \mathrm{~A}$.

Syarat mutu sement portland harus memenuhi SII-0013-81 atau SNI152049-2004.

c). Pasir (agregat halus), sebagai bahan pengeras dalam spesi/mortas merupakan agregat alami yang berasal dari letusan gunung berapi, sungai, dalam tanah, dan pantai harus memenuhi standar dimana kekerasan, ketajaman, gradasi, dan kebersihan terhadap lumpur maupun kebersihan terhadap bahan kimia harus memenuhi standart nasional Indonesia (SKSNI-S-04-1989-F:28).

Batu bata merupakan komponen utama dalam pembuatan dinding tembok. Batu

Halaman 14 Jurnal APLIKASI: Media Informasi \& Komunikasi Aplikasi Teknik Sipil Terkini 
bata terbuat dari tanah liat dicampur dengan pasir atau tambahan bahan lain seperti abu bakaran sekam atau yang lainnya kemudian dicetak, dikeringkan, dan dibakar. Standar ukuran batu bata diatur dalam SII-0021-1978 seperti pada Tabel 1.

Tabel 1. Modul standar ukuran batu bata

\begin{tabular}{cccc}
\hline Modul & $\begin{array}{c}\text { Tebal } \\
(\mathrm{mm})\end{array}$ & $\begin{array}{c}\text { Lebar } \\
(\mathrm{mm})\end{array}$ & $\begin{array}{c}\text { Panjang } \\
(\mathrm{mm})\end{array}$ \\
\hline M-5a & 65 & 90 & 190 \\
M-5b & 65 & 140 & 190 \\
M-6 & 55 & 110 & 230 \\
\hline
\end{tabular}

Sumber: SII-0021-1978

Penyimpangan maksimum ukuran batu bata diatur dalam SII-0021-1978 seperti pada Tabel 2.

Tabel 2. Toleransi penyimpangan ukuran maksimal batu bata SII-0021-1978

\begin{tabular}{ccccccc}
\hline & \multicolumn{3}{c}{ Penyimpangan ukuran maksimum (mm) } \\
\cline { 2 - 7 } Kelas & \multicolumn{3}{c}{ M-5a dan M-5b } & \multicolumn{3}{c}{ M-6 } \\
\cline { 2 - 7 } & $\begin{array}{c}\text { Te } \\
\text { bal }\end{array}$ & $\begin{array}{c}\text { Le } \\
\text { bar }\end{array}$ & $\begin{array}{c}\text { Pan } \\
\text { jang }\end{array}$ & $\begin{array}{c}\text { Te } \\
\text { bal }\end{array}$ & $\begin{array}{c}\text { be } \\
\text { bar }\end{array}$ & $\begin{array}{c}\text { Pan } \\
\text { jang }\end{array}$ \\
\hline 25 & 2 & 3 & 5 & 2 & 3 & 5 \\
50 & 2 & 3 & 5 & 2 & 3 & 5 \\
100 & 2 & 3 & 4 & 2 & 3 & 4 \\
150 & 2 & 2 & 4 & 2 & 2 & 4 \\
200 & 2 & 2 & 4 & 2 & 2 & 4 \\
250 & 2 & 2 & 4 & 2 & 2 & 4 \\
\hline Sumber: SII-0021-1978
\end{tabular}

Menurut SNI-10.1978:6, kualitas/mutu batu bata dibagi menjadi tiga tingkatan dalam hal kuat tekan dan penyimpangan ukuran. Di antaranya dapat dilihat pada Tabel 3. Kuat tekan batubata menurut standar Industri Indonesia SII-00211978 seperti pada Tabel 4.

Tegangan tekan internal yang ditimbulkan oleh gaya tekan diasumsikan tersebar/didistribusikan merata keseluruhan penampang sehingga intensitas atau tegangan yang terjadi adalah:
$\alpha=\frac{P}{A}$

dimana:

$\alpha=$ tegangan $\left(\mathrm{kg} / \mathrm{cm}^{2}\right)$

$\mathrm{P}=$ gaya tekan $(\mathrm{kg})$

$\mathrm{A}=$ luas penampang $\left(\mathrm{cm}^{2}\right)$

Tabel 3. Tingkatan mutu, kuat tekan ratarata, dan penyimpangan ukuran

\begin{tabular}{|c|c|c|}
\hline $\begin{array}{c}\text { Tingkat } \\
\text { Mutu }\end{array}$ & $\begin{array}{c}\text { Kuat Tekan } \\
\text { Rata-rata }\end{array}$ & $\begin{array}{c}\text { Penyimpangan } \\
\text { ukuran }\end{array}$ \\
\hline $\begin{array}{c}\text { Tingkat } \\
1\end{array}$ & $\begin{array}{l}\text { Lebih besar } \\
100 \mathrm{Kg} / \mathrm{Cm}^{2}\end{array}$ & $\begin{array}{c}\text { Tidak ada } \\
\text { penyimpangan }\end{array}$ \\
\hline $\begin{array}{c}\text { Tingkat } \\
2\end{array}$ & $\begin{array}{c}80-100 \\
\mathrm{Kg} / \mathrm{Cm}^{2}\end{array}$ & $\begin{array}{l}\text { Satu buah dari } \\
\text { sepuluh benda } \\
\text { percobaan }\end{array}$ \\
\hline $\begin{array}{c}\text { Tingkat } \\
3\end{array}$ & $60-80 \mathrm{Kg} / \mathrm{Cm}^{2}$ & $\begin{array}{c}\text { Dua buah dari } \\
\text { sepuluh benda } \\
\text { percobaan }\end{array}$ \\
\hline
\end{tabular}

Tabel 4. Kuat tekan dan koefisien variasi batu bata yang diijinkan SII-0021-1978

\begin{tabular}{cccc}
\hline \multirow{2}{*}{ Kelas } & $\begin{array}{c}\text { Kuat tekan rata-rata } \\
\text { minimum dari } 30 \\
\text { buah batu bata yang } \\
\text { diuji }\end{array}$ & $\begin{array}{c}\text { Koefisien variasi } \\
\text { yang diizinkan } \\
\text { dari rata-rata kuat } \\
\text { tekan }\end{array}$ \\
\cline { 2 - 4 } & $\begin{array}{c}\mathrm{kg} / \mathrm{cm}^{2} \\
\mathrm{~N} / \mathrm{mm}^{2}\end{array}$ & $\%$ \\
\hline 25 & 25 & 2.5 & 25 \\
50 & 50 & 5 & 22 \\
100 & 100 & 10 & 22 \\
150 & 150 & 15 & 15 \\
200 & 200 & 20 & 15 \\
250 & 250 & 25 & 15 \\
\hline Sumber
\end{tabular}

Sumber: SII-0021-1978

\section{Metodologi}

\subsection{Kekuatan Tekan Spesi/Mortar}

Pada penelitian terdahulu (Sukobar, 1995) Komposisi campuran kapur, pasir, dan semen dibuat berdasarkan pada komposisi yang biasa dipakai di lapangan yaitu 5 Kapur : 15 Pasir : 1 Semen (5 Kp : 15 Ps : 1 Pc), kemudian dibuat simulasi campuran dengan

Jurnal APLIKASI: Media Informasi \& Komunikasi Aplikasi Teknik Sipil Terkini Halaman 15 
bagian kapur dan pasir dibuat tetap, tetapi bagian semen $(\mathrm{Pc})$ diubah-ubah seperti yang terlihat pada Tabel 5 .

Tabel 5. Komposisi berdasarkan perbandingan volume Kapur (Kp), Pasir (Ps), dan Semen $(\mathrm{Pc})$

\begin{tabular}{cccc}
\hline \multirow{2}{*}{ Komposisi } & \multicolumn{3}{c}{ Volume (bagian) } \\
\cline { 2 - 4 } & $\mathrm{Kp}$ & $\mathrm{Ps}$ & $\mathrm{Pc}$ \\
\hline I & 5 & 15 & 0,6 \\
II & 5 & 15 & 0,7 \\
III & 5 & 15 & 0,8 \\
IV & 5 & 15 & 0,9 \\
V & 5 & 15 & 1,0 \\
VI & 5 & 15 & 1,1 \\
VII & 5 & 15 & 1,2 \\
VIII & 5 & 15 & 1,3 \\
\hline Sumber: Sukobar, 1995 & &
\end{tabular}

Masing-masing komposisi dibuat 10 benda uji, sehingga ada 80 benda uji, kemudian dites tekan pada umur 28 hari.

\subsection{Kekuatan Tekan Batu Bata}

a). Pengambilan contoh benda uji batu bata dilakukan dengan cara random dari beberapa tempat pembuatan di Kecamatan Bangsal Kabupaten Mojokerto yang dikenal dipasaran dengan sebutan bata Mojosari (Gambar 1), pengambilan contoh dilakukan pada 6 lokasi tempat pembuatan (Gambar 2), masing-masing lokasi diambil sebanyak 5 contoh benda uji sehingga total ada 30 buah contoh benda uji batu bata.

b). Pengujian Kuat Tekan Batu Bata

Dilakukan di laboratorium beton Diploma III teknik sipil ITS, sebelum dilakukan pengujian permukaan batu bata pada bagian muka dan belakang dilapisi/diratakan dengan adukan $1 \mathrm{Pc}$ :
2 Ps. Agar beban tekan dari alat uji dapat diteruskan merata ke permukaan luasan batu bata.

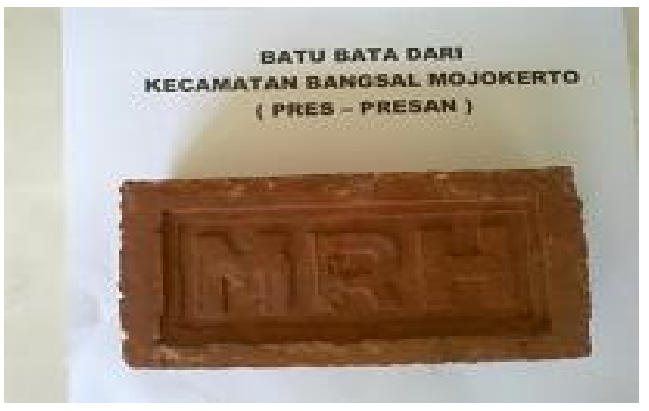

Gambar 1. Foto batu bata mojosari press

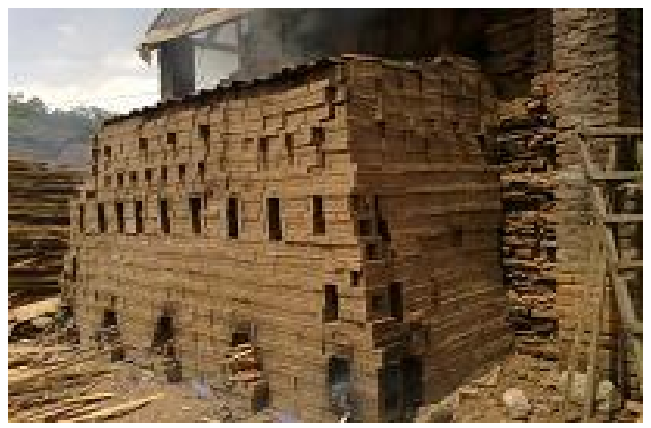

Gambar 2. Foto setelah pembakaran batu bata

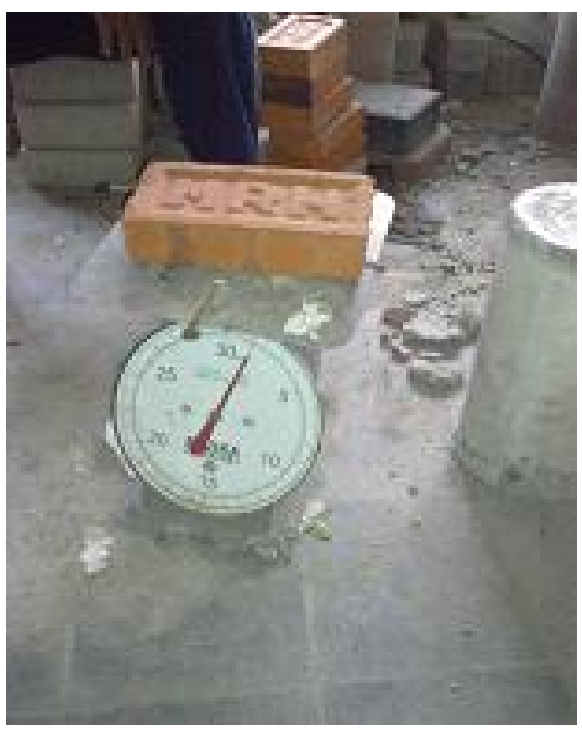

Gambar 3. Foto penimbangan batu bata

Setelah cukup umur (7 hari) setiap contoh benda uji batu bata dari 30 buah

Halaman 16 Jurnal APLIKASI: Media Informasi \& Komunikasi Aplikasi Teknik Sipil Terkini 
benda uji diukur, ditimbang beratnya, kemudian dites/diuji kuat tekannya (Gambar 3 dan 4). Nilai kuat tekan batu bata ditentukan berdasarkan nilai ratarata dari hasil pengujian kuat tekan 30 buah benda uji.

\section{Hasil dan Pembahasan}

\subsection{Kuat Tekan Spesi/Mortar Cam-} puran Kapur, Pasir, dan Semen

Kuat tekan rata-rata dan tegangan telah dilakukan penelitian terdahulu (Sukobar, 1995) seperti pada Tabel 6 dan 7.

Persamaan garis regresi seperti berikut:

$\mathrm{Y}=\mathrm{a}+\mathrm{bx}$

$b=\frac{\sum x y}{\sum x} ; a=\frac{\sum Y-L \sum x}{n}$

dimana:

$\sum x y=\sum x y-\frac{(\Sigma x) \Sigma y}{n}$

$\sum x^{2}=\sum x^{2}-\frac{\left(\sum x\right)^{2}}{n}$

$\mathrm{n}=$ Jumlah pasangan $\mathrm{X}$ dan $\mathrm{Y}$

$$
\begin{aligned}
& \sum x y=89,5-\frac{(7,6)(90,2)}{8}=3,81 \\
& \sum x^{2}=7,64-\frac{(7,6)^{2}}{8}=0,42 \\
& b=\frac{3,61}{0,42}=9,07 \\
& a=\frac{90,20-9,07(7,06)}{8}=2,66
\end{aligned}
$$

\begin{tabular}{|c|c|c|c|c|c|c|c|c|c|c|c|c|}
\hline \multirow{2}{*}{ Komposisi } & \multicolumn{10}{|c|}{ Hasil tes kuat tekan } & \multirow{2}{*}{$\begin{array}{l}\text { P rata-rata } \\
\mathrm{kg}\end{array}$} & \multirow{2}{*}{$\frac{\mathrm{P} / \mathrm{A}}{\mathrm{kg} / \mathrm{cm}^{2}}$} \\
\hline & 1 & 2 & 3 & 4 & 5 & 6 & 7 & 8 & 9 & 10 & & \\
\hline I & 1,47 & 1,45 & 1,23 & 1,43 & 1,45 & 1,35 & 1,40 & 1,56 & 1,57 & 1,48 & 1,44 & 8,14 \\
\hline II & 1,68 & 1,54 & 1,93 & 1,50 & 1,76 & 1,78 & 1,82 & 1,66 & 1,48 & 1,77 & 1,70 & 9,58 \\
\hline III & 1,70 & 1,74 & 1,82 & 1,76 & 1,76 & 1,86 & 1,80 & 1,82 & 1,80 & 1,84 & 1,79 & 10,13 \\
\hline IV & 1,88 & 1,80 & 1,92 & 1,94 & 1,94 & 1,84 & 1,86 & 1,70 & 1,88 & 1,98 & 1,86 & 10,54 \\
\hline V & 1,80 & 1,86 & 1,96 & 1,84 & 1,96 & 1,86 & 1,96 & 1,94 & 2,00 & 2,04 & 1,92 & 10,88 \\
\hline VI & 2,03 & 1,88 & 2,74 & 2,10 & 2,03 & 2,21 & 2,51 & 2,31 & 2,33 & 2,17 & 2,23 & 12,63 \\
\hline VII & 1,94 & 2,00 & 2,10 & 2,70 & 2,08 & 2,40 & 2,42 & 2,50 & 2,54 & 2,11 & 2,78 & 12,90 \\
\hline VIII & 2,66 & 2,94 & 2,39 & 2,92 & 1,99 & 2,80 & 3,05 & 2,99 & 3,03 & 2,57 & 2,73 & 15,48 \\
\hline
\end{tabular}

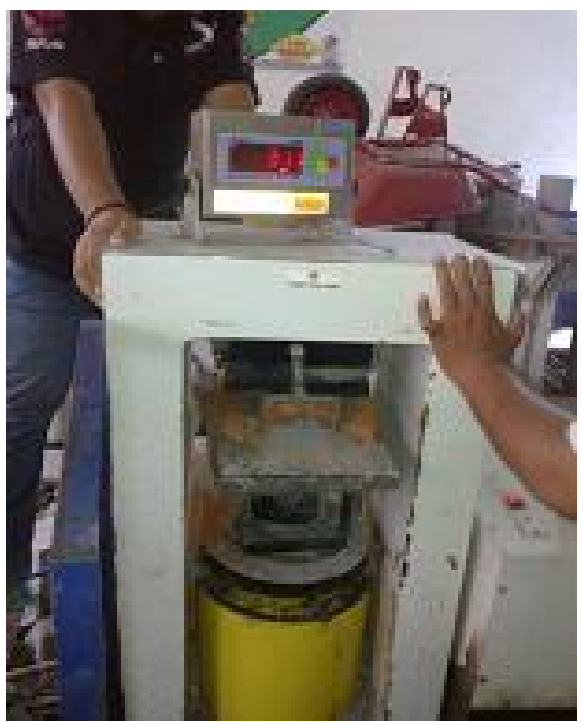

Gambar 4. Foto tes kuat tekan batu bata

Tabel 6. Hasil tes kuat tekan rata-rata spesi campuran kapur, pasir, dan semen

Sumber: Sukobar, 1995

Hubungan antara kuat tekan spesi/mortar dan kadar semen dapat digambarkan oleh persamaan garis regresi sebagai berikut (Tabel 8):

$\mathrm{Y}=2,66+9,07 \mathrm{X}$ dimana:

$\mathrm{Y}=$ kuat tekan $\left(\mathrm{kg} / \mathrm{cm}^{2}\right)$

$\mathrm{X}=$ kadar/bagian semen

3.2 Pengujian Kuat Tekan Batu Bata

Jurnal APLIKASI: Media Informasi \& Komunikasi Aplikasi Teknik Sipil Terkini Halaman 17 
Hasil pengujian dari 30 contoh benda uji batu bata yang terlihat pada Tabel 9 .

Tabel 7. Tegangan untuk masing-masing komposisi (Campuran berdasarkan perbandingan volume).

\begin{tabular}{clc}
\hline Komposisi & $\begin{array}{c}\text { Campuran berdasarkan } \\
\text { perbandingan volume }\end{array}$ & $\begin{array}{c}\text { Tegangan } \\
\left(\mathrm{kg} / \mathrm{cm}^{2}\right)\end{array}$ \\
\hline I & $5 \mathrm{Kp}: 15 \mathrm{Ps}: 0,60 \mathrm{Pc}$ & 8,14 \\
II & $5 \mathrm{Kp}: 15 \mathrm{Ps}: 0,76 \mathrm{Pc}$ & 9,58 \\
III & $5 \mathrm{Kp}: 15 \mathrm{Ps}: 0,80 \mathrm{Pc}$ & 10,13 \\
IV & $5 \mathrm{Kp}: 15 \mathrm{Ps}: 0,90 \mathrm{Pc}$ & 10,54 \\
V & $5 \mathrm{Kp}: 15 \mathrm{Ps}: 1,00 \mathrm{Pc}$ & 10,88 \\
VI & $5 \mathrm{Kp}: 15 \mathrm{Ps}: 1,10 \mathrm{Pc}$ & 12,63 \\
VII & $5 \mathrm{Kp}: 15 \mathrm{Ps}: 1,20 \mathrm{Pc}$ & 12,90 \\
VIII & $5 \mathrm{Kp}: 15 \mathrm{Ps}: 1,30 \mathrm{Pc}$ & 15,48 \\
\hline Sumber: Sukobar, 1995 &
\end{tabular}

\section{Simpulan}

Dari hasil analisa yang telah dilakukan dapat ditarik beberapa kesimpulan sebagai berikut: a. Berdasarkan ukuran, maka batu bata dari Mojosari tidak sesuai SII-00211978.

b. Dari hasil pengujian kuat tekan ratarata batu bata Mojosari sebesar $149,85 \mathrm{~kg} / \mathrm{cm}^{2}$ berdasarkan SII-00211978, maka batu bata press Mojosari termasuk kedalam tingkat mutu 1 (kuat tekan rata-rata lebih besar 100 $\mathrm{kg} / \mathrm{cm}^{2}$ ).

c. Dari hasil analisa yang telah dilakukan jika dikonversikan ke persamaan Regresi $\mathrm{Y}=2,66+9,07$ $\mathrm{X}$, maka dihasilkan kadar semen (x) $=(149,85-2,66): 9,07=16$ bagian, sehingga kuat tekan rata-rata batu bata Press dari Mojosari setara dengan kekuatan tekan spesi campuran $5 \mathrm{Kp}$ : $15 \mathrm{Ps}: 16 \mathrm{Pc}$.

Tabel 8. Hubungan Antara perubahan volume semen dan kuat tekan spesi

\begin{tabular}{cccccc}
\hline Komposisi & Perubahan volume semen & Kuat tekan spesi & \multicolumn{3}{c}{ Dibulatkan } \\
\hline I & $\mathrm{X}$ & $\left(\mathrm{kg} / \mathrm{cm}^{2}\right)$ & $\mathrm{Y}$ & $\mathrm{X}^{2}$ & $\mathrm{XY}$ \\
\hline II & 0,60 & 8,14 & 8,10 & 0,36 & 4,86 \\
III & 0,70 & 9,58 & 9,60 & 0,49 & 6,72 \\
IV & 0,80 & 10,13 & 10,10 & 0,64 & 8,08 \\
V & 0,90 & 10,54 & 10,50 & 0,81 & 9,45 \\
VI & 1,00 & 10,88 & 10,90 & 1,00 & 10,90 \\
VII & 1,10 & 12,63 & 12,60 & 1,21 & 13,90 \\
VIII & 1,20 & 12,94 & 12,90 & 1,44 & 15,50 \\
Jumlah & 1,30 & 15,48 & 15,50 & 1,69 & 20,20 \\
\hline
\end{tabular}

Sumber: Sukobar, 1995.

Halaman 18 Jurnal APLIKASI: Media Informasi \& Komunikasi Aplikasi Teknik Sipil Terkini 


\section{ISSN. 1907-753X}

Tabel 9. Kuat tekan, berat dan ukuran batu bata Mojosari

\begin{tabular}{|c|c|c|c|c|c|c|c|}
\hline \multirow{2}{*}{$\begin{array}{c}\text { No. } \\
\text { Benda uji }\end{array}$} & \multirow{2}{*}{$\begin{array}{c}\text { Berat } \\
(\mathrm{kg})\end{array}$} & \multicolumn{3}{|c|}{ Ukuran (mm) } & \multirow{2}{*}{$\begin{array}{l}\text { Luas bidang } \\
\text { tekan }\left(\mathrm{cm}^{2}\right)\end{array}$} & \multirow{2}{*}{$\begin{array}{l}\text { Beban uji } \\
\text { maksimum } \\
(\mathrm{kg})\end{array}$} & \multirow{2}{*}{$\begin{array}{c}\text { Tegangan } \\
\text { tekan } \\
\left(\mathrm{kg} / \mathrm{cm}^{2}\right)\end{array}$} \\
\hline & & Tebal & Lebar & Panjang & & & \\
\hline 1 & 1,30 & 45 & 95 & 195 & 185,25 & 25200 & 136,03 \\
\hline 2 & 1,31 & 45 & 95 & 195 & 185,26 & 28800 & 155,47 \\
\hline 3 & 1,32 & 45 & 95 & 195 & 185,27 & 25800 & 139,27 \\
\hline 4 & 1,33 & 45 & 95 & 195 & 185,28 & 18900 & 102,02 \\
\hline 5 & 1,34 & 45 & 95 & 195 & 185,29 & 27000 & 145,75 \\
\hline 6 & 1,35 & 45 & 95 & 195 & 185,30 & 24400 & 131,71 \\
\hline 7 & 1,36 & 45 & 95 & 195 & 185,31 & 28300 & 152,77 \\
\hline 8 & 1,37 & 45 & 95 & 195 & 185,32 & 26500 & 143,05 \\
\hline 9 & 1,38 & 45 & 95 & 195 & 185,33 & 28500 & 153,85 \\
\hline 10 & 1,39 & 45 & 95 & 195 & 185,34 & 29000 & 156,55 \\
\hline 11 & 1,40 & 45 & 95 & 195 & 185,35 & 27400 & 147,91 \\
\hline 12 & 1,41 & 45 & 95 & 195 & 185,36 & 31100 & 167,88 \\
\hline 13 & 1,42 & 45 & 95 & 195 & 185,37 & 23600 & 127,40 \\
\hline 14 & 1,43 & 45 & 95 & 195 & 185,38 & 23700 & 127,94 \\
\hline 15 & 1,44 & 45 & 95 & 195 & 185,39 & 31300 & 168,96 \\
\hline 16 & 1,45 & 45 & 95 & 195 & 185,40 & 29800 & 160,86 \\
\hline 17 & 1,46 & 45 & 95 & 195 & 185,41 & 31000 & 167,34 \\
\hline 18 & 1,47 & 45 & 95 & 195 & 185,42 & 29600 & 159,78 \\
\hline 19 & 1,48 & 45 & 95 & 195 & 185,43 & 28100 & 151,69 \\
\hline 20 & 1,49 & 45 & 95 & 195 & 185,44 & 27800 & 150,07 \\
\hline 21 & 1,50 & 45 & 95 & 195 & 185,45 & 29400 & 158,71 \\
\hline 22 & 1,51 & 45 & 95 & 195 & 185,46 & 30100 & 162,48 \\
\hline 23 & 1,52 & 45 & 95 & 195 & 185,47 & 31000 & 167,34 \\
\hline 24 & 1,53 & 45 & 95 & 195 & 185,48 & 29600 & 159,78 \\
\hline 25 & 1,54 & 45 & 95 & 195 & 185,49 & 28100 & 151,69 \\
\hline 26 & 1,55 & 45 & 95 & 195 & 185,50 & 28000 & 151,15 \\
\hline 27 & 1,56 & 45 & 95 & 195 & 185,51 & 2600 & 143,59 \\
\hline 28 & 1,57 & 45 & 95 & 195 & 185,52 & 27900 & 150,61 \\
\hline 29 & 1,58 & 45 & 95 & 195 & 185,53 & 28200 & 152,23 \\
\hline 30 & 1,59 & 45 & 95 & 195 & 185,54 & 28100 & 151,69 \\
\hline Rata-rata & 1,60 & 45 & 95 & 195 & 185,55 & 27760 & 149,85 \\
\hline
\end{tabular}

\section{Daftar Pustaka}

Erlangga Satria Agung, (2013), REI optimistis bangun 20.000 unit rumah sederhana.

GERE, J.M., Timoshenko, S.P., Waspakrik, H. J., (1987), Mekanika
Bahan Edisi Kedua Versi S. I, Penerbit Erlangga; Jakarta.

Muko muko, J.A. (1977), Dasar Penyusunan Anggaran Biaya Bangunan, Kurnia Esa; Jakarta.

Ritonga, Abdulrahman. (1987), Statistika Terapan Untuk Penelitian,

Jurnal APLIKASI: Media Informasi \& Komunikasi Aplikasi Teknik Sipil Terkini Halaman 19 
Lembaga Penerbitan Fakultas Ekonomi U.I; Jakarta.

SK SNI-S-04-1989-F:28, (1989), Syarat-syarat aggregate halus untuk campuran pembuatan beton, Standard Nasional Indonesia.

SII-0021-1978, Kelas Toleransi dan Modul Standart Ukuran Batu Bata, Standart Industri Indonesia.

SII.0013-81, (1981), Mutu dan Cara Uji Semen Portland.

Sukobar, Imron harun. (1995), Kekuatan Tekan Spesi Campuran Semen, Kapur, Pasir untuk Pasangan Bata, Laporan Penelitian, Surabaya.

SNI-10.1978:6, (1978), Standar Nasional Indonesia Kuat Tekan dan Penyimpangan Ukuran Batu Bata.

SNI 15-7064-2004, (2004), Standar Nasional Indonesia Semen Portland Komposit.

Yayasan Penyelidikan Masalah Bangunan. (1984), Syarat-syarat untuk Kapur Bahan Bangunan NI-7, Yayasan LPMB; Bandung. 